Research Article

\title{
Study on Soil Spring Model for Pipe and Silty Clay Interaction Based on Physical Model Test
}

\author{
Liyun Li $\left(\mathbb{D},{ }^{1,2}\right.$ Junyan Han, ${ }^{1}$ and Xiangjian Wang ${ }^{2}$ \\ ${ }^{1}$ Key Laboratory of Urban Security and Disaster Engineering of Ministry of Education, Beijing University of Technology, \\ Beijing 100124, China \\ ${ }^{2}$ Institute of Engineering Mechanics, China Earthquake Administration, Harbin 150080, China \\ Correspondence should be addressed to Liyun Li; llyun5921@sina.com
}

Received 28 July 2020; Revised 5 February 2021; Accepted 22 February 2021; Published 5 March 2021

Academic Editor: Patrice Berthod

Copyright (C) 2021 Liyun Li et al. This is an open access article distributed under the Creative Commons Attribution License, which permits unrestricted use, distribution, and reproduction in any medium, provided the original work is properly cited.

\begin{abstract}
The previous soil spring model cannot describe the nonlinear characteristics of soil in elastic stage, and there are some shortcomings in the selection of soil spring parameters in some published codes. Meanwhile, the literatures about the spring model for pipe and silty clay interaction are rare. Thus, a series of pipe-silty clay interaction tests are conducted, and some corresponding experimental results are obtained. The effects of soil properties, pipe diameter, and embedment depth on the horizontal resistance of soil are studied. Based on the experimental results, the failure modes of soil are analysed, and a formula to calculate the peak resistance of soil and the corresponding displacement to peak resistance are proposed. Finally, a method to describe the nonlinear spring stiffness coefficient of silty clay is recommended.
\end{abstract}

\section{Introduction}

In the analysis and design of buried pipeline, soil spring model is often adopt to describe the action of soil on the pipeline, in which the soil around pipeline is equivalent to a three-dimensional soil spring, and many fruits have been obtained based on the soil spring model [1-10]. For the transverse soilpipe interaction, it is common practice to idealize the resistance displacement curve into a linear elastic-perfectly plastic model represented by two straight lines, as shown in Figure 1, so that the properties of soil spring can be determined by getting the peak soil resistance and its corresponding displacement. In the past forty years, a great deal of studies has been in progress on the two parameters of transverse soil spring. Audibert et al. [11] discussed the binding force of soil to pipeline in pipe-soil interaction. Trautmann and O'Rourke [12] conducted a model test of pipe-sand interaction and suggested a method for determining the parameters of transverse soil spring in sandy soil. Yimsiri et al. [13] analysed the lateral and upward pipe movements at different embedment conditions in order to find the solution for the peak force and to investigate its transition from shallow to deep failure mechanism. Guo et al. [14] discussed the sensitivity of influencing factors of pipe-soil interaction in sandy soil by the finite element method and analysed the influence of buried depth and pipe diameter on value of soil spring parameters. Badv and Daryani [15] investigated the response of buried pipelines in sand to transverse PGD with particular attention to the peak forces exerted on the pipe. Liu et al. [16] carried out some model tests on the restraint effect of sand on buried pipelines in fine sand of Bohai region, for revealing the exertion process of soil resistance during vertical, horizontal, and axial movement of pipelines in sand. Jung et al. [17] simulated the lateral force versus displacement relationship of pipelines under planestrain conditions in both dry and partially saturated sand and discussed the relationship between the maximum lateral force and pipe depth in dense sand. Based on Trautmann's experimental work [12], Li et al. [18] analysed the sensitivity of influencing factors of pipe-sand interaction by the numerical method and proposed an empirical formula to get the ultimate bearing capacity of sand under large-depth. Robert et al. [19] studied the lateral load-displacement behaviour of pipelines in partially saturated sand. Concerning the study of 


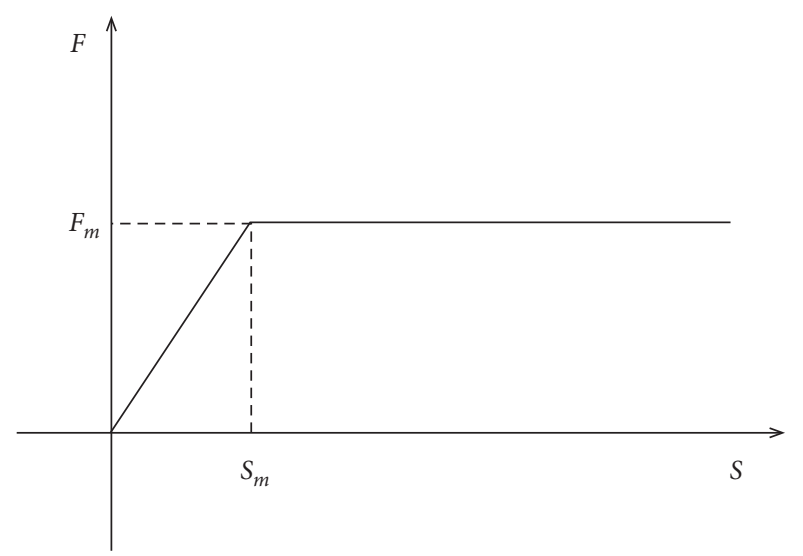

Figure 1: General soil spring model.

pipe-soil interaction in clayey soil, Oliveira et al. [20] carried out the centrifuge physical model test of pipe-soft clay interaction and proposed a method for calculating the ultimate bearing capacity of soft clay when the pipeline moved laterally. Liu et al. [21-23] conducted a series of pipe-soil interaction model tests on soft clay in Bohai region, analyzed the failure mode of the soil, and proposed a formula for calculating the peak resistance of soil.

All the above studies assumed that the soil around the pipe is an ideal elastic-plastic material, which is inconsistent with the nonlinear characteristics of the elastic mechanical segment of soil material. Moreover, most of the previous studies focused on sand. There are few studies on pipe-soil interaction in clayey soil, and the research object of pipe-clay interaction is only on saturated soft clay. In the construction of directly buried pipelines in Beijing region, the backfilling into the trench is usually made of clay materials, such as clayey silt, silty clay, or clay, which are taken from the construction area. These clayey materials are mostly above the groundwater level and belong to unsaturated soils. The matrix suction among solid, liquid, and gas phases in soils makes the properties of unsaturated soils significantly different from those of saturated soils and dry soils. Few studies published focus on the effect of moisture content in clayey soil on pipesoil interaction. Besides, the Code for Seismic Design of Outdoor Water Supply, Drainage and Gas Thermal Engineering in China [24] and American Lifelines Alliance [25] recommended the same method for calculating the peak bearing capacity of clayey soil, but there are differences in the unit of soil parameters, which need to be checked. In view of the above discussion, the authors carried out some physical model tests of pipe-soil interaction with the silty clay in Beijing region. Based on the experimental results, the authors discuss the determination of key parameters of soil spring and the mathematical description of soil spring coefficient, in order to provide an experimental basis for the laying of pipelines in silty clay site in Beijing region.

\section{Physical Model Tests}

Figure 2 shows the photo of experiment device, in which, the test container is welded by steel plate, with the size of



Figure 2: Model test device.

$1000 \mathrm{~mm} \times 500 \mathrm{~mm} \times 1100 \mathrm{~mm}$ (length $\times$ width $\times$ height $).$ A plexiglass observation window of $900 \mathrm{~mm} \times 700 \mathrm{~mm}$ is arranged on the front panel of container for observing the deformation and failure process of soil during test. There are two parallel vertical joints on the right panel of the container for the steel strand to pass through. The actuator and the test pipe are connected by two steel strands, and the force and the movement are automatically recorded via the actuator acquisition system. Figure 3 shows the connection between the steel strand and the test pipe.

The test pipes are steel tubes with the length of $490 \mathrm{~mm}$. The diameter of the pipes are the four common sizes in pipe engineering, which are $30 \mathrm{~mm}, 60 \mathrm{~mm}, 102 \mathrm{~mm}$, and $140 \mathrm{~mm}$, respectively. The test results of $60 \mathrm{~mm}$ diameter pipe are as the benchmark to analyse the influence of pipe diameter on the horizontal resistance of soil.

The test soil is the typical silty clay in Beijing region. Its plastic limited moisture content is $15 \%$, liquid limited moisture content is $29 \%$, and natural moisture content is $16 \%$. Four soil samples reconstituted by controlling the moisture content and dry unit weight of the soil are in stiff, hard plastic and plastic state, respectively. The measured cohesive force and measured internal friction angle of these soil samples are listed in Table 1, which are obtained by static triaxial test. As shown in Table 1, the change of cohesive force and internal friction angle of silty clay is in good agreement with those in literature [26], that is, the cohesive force and internal friction angle decreases with the increase of water content in silty clay.

The test cases are shown in Table 2, of which, the first to fourth cases are to analyse the effect of the depth-diameter ratio $(H / D)$ and the soil properties on the test results and the fifth case is to investigate the effect of pipe diameter.

During the tests, the Earth pressure acting on the pipe wall is also monitored. Since there is only the upstream surface of pipe interacting with soil in the test process, seven Earth pressure sensors are arranged at $30^{\circ}$ intervals on the upstream surface of pipe which interacts with soil. The FlexiForce sensor produced by Tekscan company, a kind of thin film pressure sensor, is used to measure the Earth pressure on pipe in test. Figure 4 shows the location of pressure sensors on pipe and a photo of thin film pressure sensor. The thin film Earth pressure sensor consists of a circular pressure sensing area, a flat wire, and a pin. The pin is connected with the data acquisition system through a connecting wire. The thin film Earth pressure sensor is a 


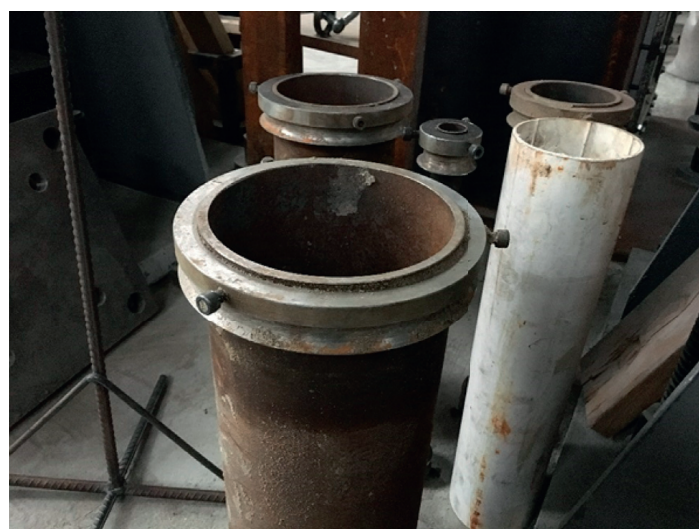

(a)

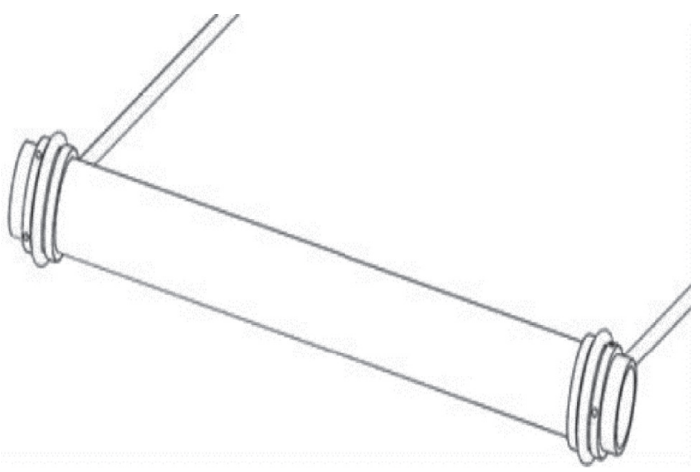

(b)

FIGURE 3: Connection between the steel strand and the test pipe. (a) Fixing device of the steel strand on the test pipe. (b) Schematic diagram of the fixed steel strand.

TABle 1: Parameters of soil property.

\begin{tabular}{lccccc}
\hline Sample & Dry unit weight $\gamma_{d}\left(\mathrm{kN} / \mathrm{m}^{3}\right)$ & Moisture content $\omega(\%)$ & Plastic index $I_{p}$ & Cohesive force $\mathrm{c}(\mathrm{kPa})$ & Internal friction angle $\varphi\left(^{\circ}\right)$ \\
\hline I & \multirow{2}{*}{16.0} & 10 & & 161.0 & 12.1 \\
II & & 16 & 14 & 136.4 & 10.2 \\
III & \multirow{2}{*}{17.0} & 20 & & 50.3 & 8.8 \\
IV & & 16 & 64.9 & 23.3 \\
\hline
\end{tabular}

TABLE 2: Test cases.

\begin{tabular}{lccccc}
\hline Case & Sample & $\begin{array}{c}\text { Test soil } \\
\text { Consistency state }\end{array}$ & Diameter of tube $(\mathrm{mm})$ & Depth-diameter ratio $H / D$ & Loading mode \\
\hline 1 & I & Stiff & 60 & $1 / 3 / 5 / 7 / 10$ & Lateral displacement loading \\
2 & II & Hard plastic & 60 & $1 / 3 / 5 / 8 / 10$ & $1 / 3 / 4 / 5 / 6 / 7$ \\
3 & III & Plastic & 60 & $1 / 3 / 5 / 7 / 10$ & 3 \\
4 & IV & Hard plastic & 60 & $30 / 60 / 102 / 140$ & \\
5 & IV & Hard plastic &
\end{tabular}

Note. $H$ indicates the distance from the upper surface of soil to the axis of tube; $D$ means the outer diameter of tube, all the same as below.



(a)

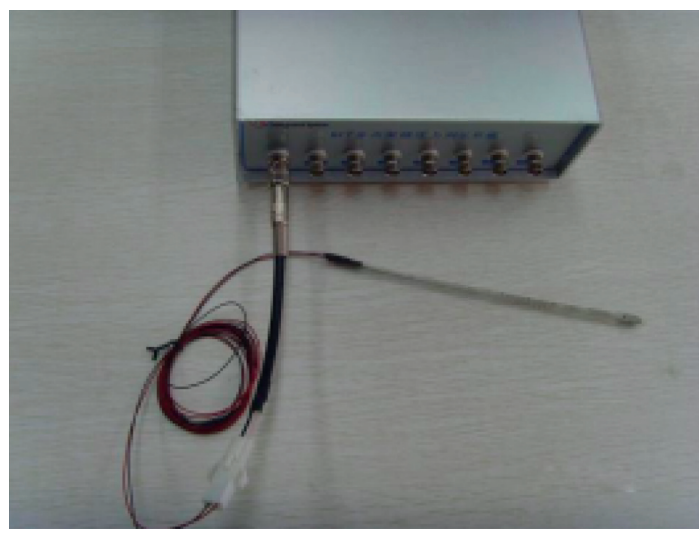

(b)

FIgURE 4: Monitoring of Earth pressure. (a) Location of the pressure sensor on the pipe. (b) Thin film pressure sensor. 
piezoelectric sensor, and the relationship between pressure and current is linear. Thus, the Earth pressure acting on the pipe can be obtained by changing the current value.

The test process is as follows:

Stage 1. According to the dry unit weight of soil designed for test, the total mass of soil required is calculated, and then, a sufficient mass of soil with corresponding moisture content is made for standby.

Stage 2. The compacted soil of $0.45 \mathrm{~m}$ thick is laid in the test container to ensure that there is enough soil under pipe to reduce the influence of the bottom boundary on test results. In order to ensure the uniformity of the compacted soil, the soil of $0.45 \mathrm{~m}$ thick is evenly divided into 9 layers for compaction. After each layer of soil is compacted, the soil surface shall be scratched to ensure that it is rough enough, and then, the next layer of soil is laid.

Stage 3. Place the test pipe at the specified location in the test container (as shown in Figure 5).

Stage 4. Lay the remaining soil to the design height in the same way as above.

Stage 5. Connect the actuator and steel strand, and adjust the actuator to ensure that the test pipe is pulled horizontally. Then, start the actuator and pull the pipeline horizontally with speed of $0.5 \mathrm{~mm} / \mathrm{s}$, record the soil resistance and the displacement of the pipe at each moment via the actuator acquisition system, and take the images of the whole test process with a camera.

In order to ensure the consistency of the undrained shear strength between each layer of silty clay, three stages were carried out in the test.

Stage 1: prepare test soil with designed moisture content. (1) The soil is air-dried and the moisture content of the soil is measured every day. When the moisture content is lower than $10 \%$, the air drying is stopped. (2) The amount of water required for test soil with designed water content is calculated. (3) According to the calculated amount of water, the soil is mixed with airless water. When mixing, the amount of soil taken out each time is not more than $30 \mathrm{~kg}$, the required water is sprayed into water mist with pressure spout, and the soil is constantly turned to ensure the uniformity of water in soil. (4) The moisture content of the prepared soil sample is measured to ensure that it meets the test requirements.

Stage 2: test the undrained shear strength standard of clay with different dry unit weight. (1) According to the requirements of triaxial test, the weight of soil with designed dry weight is calculated. (2) Soil samples for triaxial test are prepared. (3) Triaxial test is carried out, and the undrained shear strength of clay with different dry unit weights is obtained.

Stage 3: prepare the model test according to the experimental design. (1) The height mark line on the glass window of the test container is drawn. (2) The weight of each clay layer according to the designed dry unit weight and moisture content is calculated. (3) The soil is compacted to set height for each soil layer. (4) The surface of the compacted soil is roughened, and then, the next layer of soil is laid on it. (5) Repeat (3) to (4) until the design height is reached.

Meanwhile, when filling the soil layer where the test pipe is located, the $0.5 \mathrm{D}$ thick soil layer is filled and compacted firstly, and then, a semicircular trench with diameter of $1.0 \mathrm{D}$ is excavated at the designed position of pipe, and the test pipe is put into the trench. After that, the subsequent soil layers are filled. It should be noted that the soil around the pipe is compacted with compaction tools close to the side wall of the pipe with light load and multiple compaction, and the filling of the soil layer above the pipe shall be carried out with light load and multiple compaction, so as to minimize the influence of the pipe on the lower soil layer.

\section{Reliability Verification of Experiment}

In order to check the reliability of the experimental results, the physical model tests in this paper are simulated by using ABAQUS finite element software. The influence of model scale on experimental results is analysed, and the physical model test results are corrected.

3.1. Numerical Modelling Method. During the tests, the deformation of soil belongs to plane strain problem. Therefore, the two-dimensional model is used for numerical simulation. In order to ensure the accuracy of numerical calculation and sufficient calculation efficiency, the following principles are adopted to mesh the elements: the element size of the soil under the pipe is $0.03 \mathrm{~m} \times 0.06 \mathrm{~m}$, and the element size in front of and above the pipe is $0.015 \mathrm{~m} \times 0.015 \mathrm{~m}$. As we know, the area of pipe-soil interaction is the key domain of numerical calculation, so the element size in this area is locally refined to $0.005 \mathrm{~m} \times 0.005 \mathrm{~m}$. Figure 6 presents the element mesh of a numerical model.

The boundary of the numerical model is treated by constraining the displacement of nodes on the truncated boundary, that is, the horizontal and vertical displacements of nodes on the upper surface of the model are not restricted, the displacements on the bottom of model are frozen, and only the normal horizontal movement of nodes on the other rest surface are prohibited.

The element of CPE4R is a kind of self-contained element type in ABAQUS, which represents quadrilateral linear-reduced integral plane strain element. This element type can also obtain more accurate results when the element is distorted, which is suitable for the plane strain problem. Therefore, the element of CPE4R is selected for soil.

Because the deformation of the steel pipe is very small in the test, it can be regarded as a rigid body, so the rigid element of R2D2, which is a two-dimensional linear discrete rigid element with infinite stiffness in ABAQUS, is chosen to mesh the pipe.

The contact between the pipe and soil is set by penalty function and hard contact method, and the friction coefficient is 0.2 according to the work of literature [27]. 


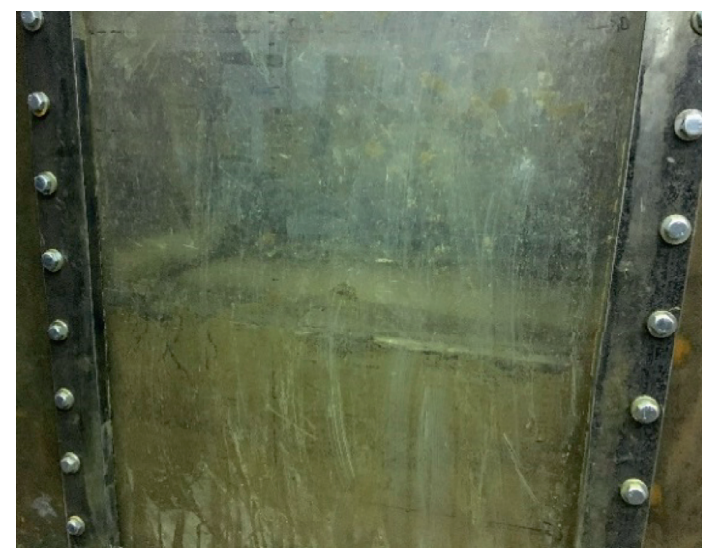

(a)

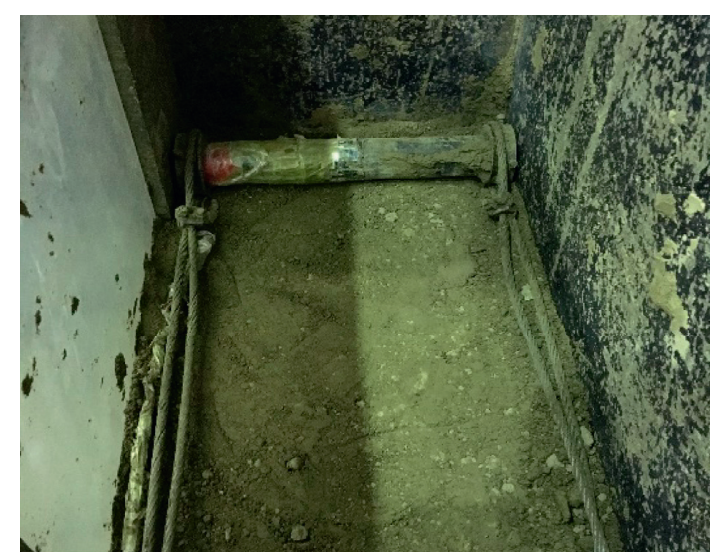

(b)

Figure 5: Place the test pipe at the designated position. (a) Side view of pipe placement. (b) Top view of pipe placement.



Figure 6: Element meshes of a numerical model.

In terms of constitutive relation, the constitutive relationship of soil is described by the Mohr-Coulomb model, in which the major parameters are cohesion force, friction angle, dilatancy angle, elastic modulus, Poison's ratio, and density.

(1) Dilatancy Angle. The soil used in this test is remolded soil, and the dilatancy of soil is very small. So, the value of the dilatancy angle is determined as follows: when friction angle $\varphi<30^{\circ}, \psi=0$, and when friction angle $\varphi>30^{\circ}, \psi=\varphi-30$.

(2) Elastic Modulus. The empirical calculation formula of elastic modulus of cohesive soil proposed by $\mathrm{Ou}$ [28] is adopted:

$$
E_{i}=C_{0} \times \eta \times S_{u}
$$

in which $C_{0}$ is related to the over consolidation ratio (OCR) of soil, which is taken as 1.0 in this paper, $\eta$ is related to the plasticity index of soil, which is taken as 800 in this paper, and $S_{u}$ is the undrained shear strength of soil.
(3) Cohesion Force and Friction Angle. The cohesion force and the internal friction angle of test soil are obtained by static triaxial test, of which the stress environment is different from that of plane strain state. Therefore, based on the data obtained from the physical model test, the parameters of cohesion and internal friction angle are inversed, and the cohesion force and internal friction angle obtained from inversion are employed in the numerical simulation.

It is considered that the pipe has been buried for a long time and the pipe-soil system has reached the equilibrium state; therefore, only the initial geo-stress of the pipe-soil model before the horizontal tensile test is balanced in numerical simulation. The specific numerical implementation is as follows. The vertical downward gravity load is applied to the pipe-soil model, and the stress field under gravity is calculated. Then, the obtained stress field is applied to the pipe-soil model in reverse. The reverse applied stress field and gravity load make the pipe-soil model in a state of initial stress existence but no initial deformation, that is, to achieve the initial stress balance. After that, a displacement is directly applied to the pipe, and the loading displacement is $0.15 \mathrm{~m}$, which is consistent with the physical model test. The dynamic explicit algorithm is used in the numerical calculation, so it is necessary to reduce the loading speed as much as possible to reduce the influence of inertial force in order to simulate the quasi-static test process of the pipe-soil interaction model. After the calculation, the relationship between the reaction force and displacement on pipe is extracted.

Figure 7 compares the experimental results and the numerical results of soil with dry unit weight of $16 \mathrm{kN} / \mathrm{m}^{3}$ and moisture content of $16 \%$ under $H / D=1,3,5$, respectively. As shown in Figure 7(a), the soil resistance displacement curve is basically consistent in the initial loading stage under $H / D=1$. However, the numerical results are greater than the physical experimental results in the postpeak stage, and the most relative error is 30\%. However, in Figure 7(b), the soil resistance displacement curve is basically consistent in the postpeak stage, and the most relative 




(a)

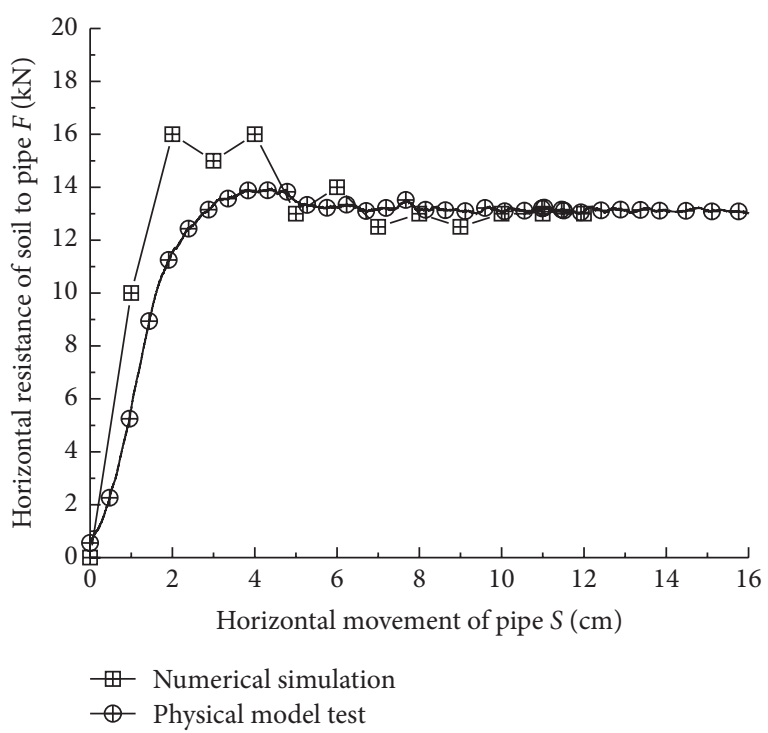

(b)



(c)

Figure 7: Load displacement curve under different $H / D$. (a) $H / D=1$. (b) $H / D=3$. (c) $H / D=5$.

error is $33 \%$ under $H / D=3$. Different from that of $H / D=1$ and $H / D=3$, there are some errors between the numerical results and the experimental results in the initial stage and the postpeak stage when $H / D=5$ (as shown in Figure $7(\mathrm{c})$ ), but the maximum error is only $25 \%$. Figure 7 indicates that the soil resistance displacement curve obtained from numerical simulation and physical model test is basically consistent under different depth diameter ratios, and the displacement corresponding to peak resistance and peak resistance is in good agreement.

In order to reveal the influence of the model scale on the results and check the reliability of the physical test, the boundary effect of the model is analysed by using the numerical model established in this paper. Figure 8 gives the resistance displacement curves of soil under different distances between the pipe and truncated boundary, in which the diameter of the pipe is $60 \mathrm{~mm}$, the depth diameter ratio $H / D$ equals 5 , the dry unit weight of soil is $16 \mathrm{kN} / \mathrm{m}^{3}$, and the moisture content of soil is $16 \%$. The results mean that the distance between the pipe and the rear boundary/the bottom boundary has little effect on the results, but the distance between the pipe and the front boundary has a great influence on the results. From Figure 8, when the distance between the front boundary and pipe axis is greater than 0.55 , the calculation results have good convergence, and the test results do not need to be corrected; when the distance between the pipe axis and the front boundary is less than $0.55 \mathrm{~m}$, the results need to be corrected. According to the numerical calculation results, the physical experimental results are corrected. The correction coefficient is shown in Table 3, in which the correction coefficient is obtained by comparing the maximum resistance from the numerical 


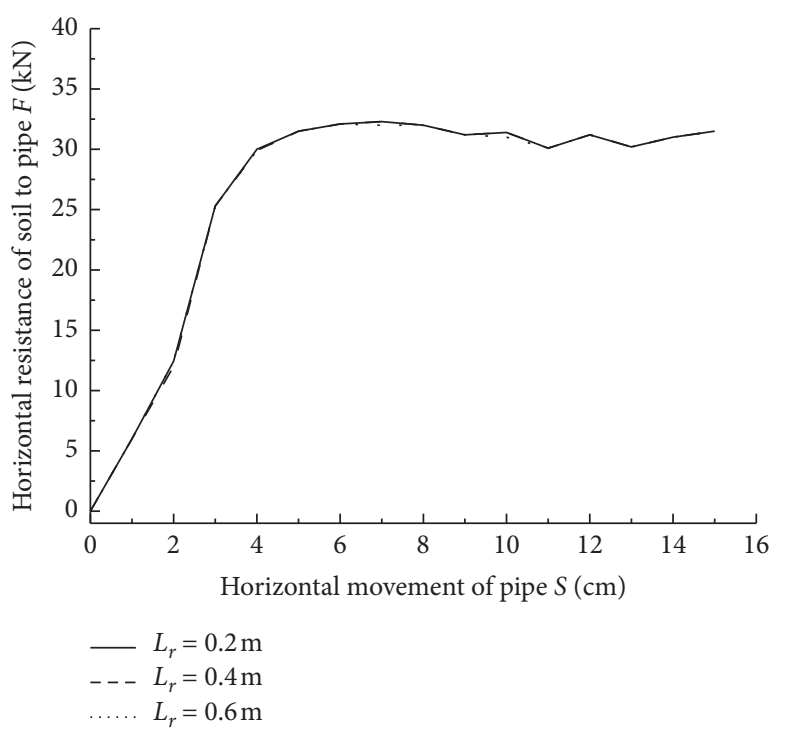

(a)

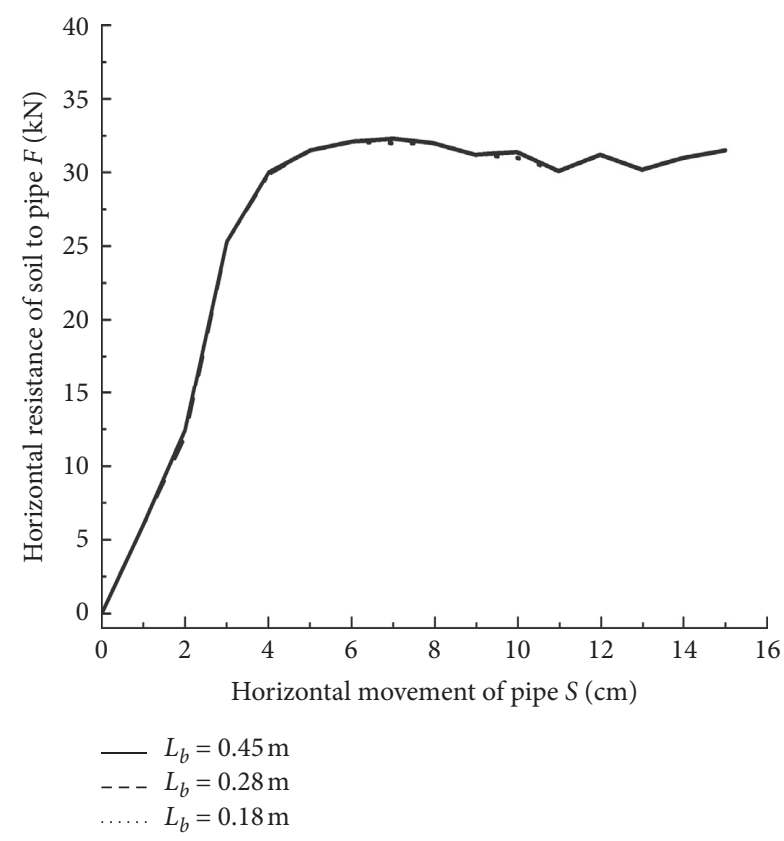

(b)

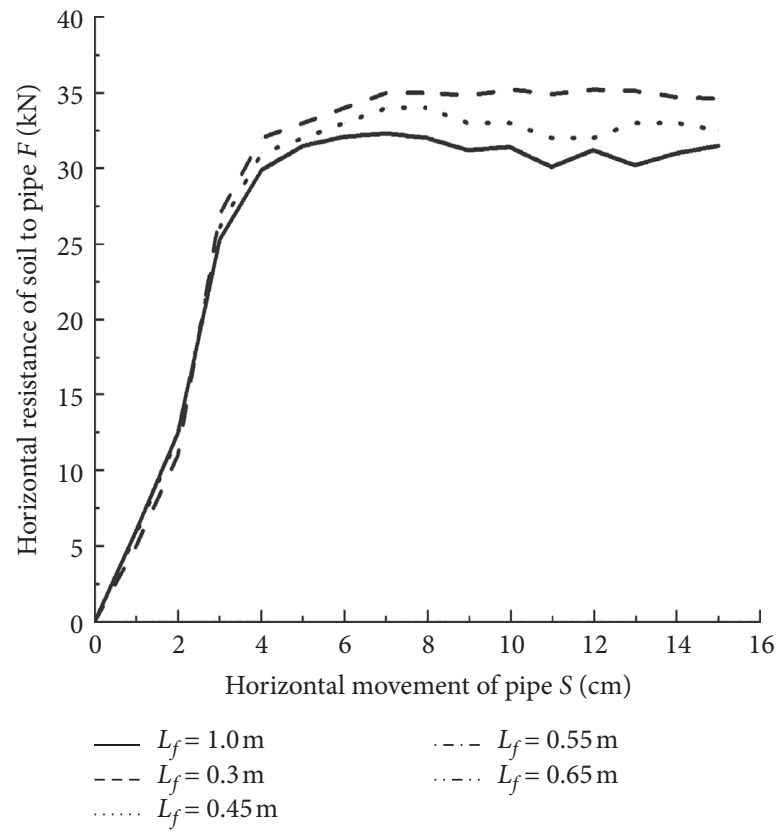

(c)

Figure 8: Resistance displacement curves under different boundary distances, in which the diameter of tube is $60 \mathrm{~mm}$, the depth diameter ratio $H / D$ equals 5 , the dry unit weight of soil is $16 \mathrm{kN} / \mathrm{m}^{3}$, and the moisture content of soil is $16 \%$. (a) The rear boundary. (b) The bottom boundary. (c) The front boundary.

simulation of far boundary to that from the simulation of the actual model test. The discussion of the following results is based on the corrected experimental data.

\section{Results and Discussion}

4.1. Resistance Displacement Curve. Figure 9 shows the resistance displacement curves of the soil around the pipe with different depth-diameter ratios at $D=60 \mathrm{~mm}$. Figures 9(a)- 9(d) demonstrate the variation of soil lateral resistance with movement of the pipe in case $1,2,3$, and 4 , respectively. The vertical coordinate is the horizontal soil resistance on the pipe of per unit length, and the abscissa coordinate is the horizontal movement of the pipe. The arrow on the curve points to the peak soil resistance of each curve.

As shown in Figure 9, the exertion process of soil resistance is different in different cases. In case 1 , the form of the resistance-displacement curves under different depth- 
TABLE 3: Correction factor of test results.

\begin{tabular}{|c|c|c|c|c|c|c|c|c|c|c|}
\hline \multirow{2}{*}{ Case } & \multicolumn{2}{|c|}{ Parameters of soil property } & \multirow{2}{*}{ Diameter of tube (mm) } & \multicolumn{7}{|c|}{ Depth-diameter ratio $H / D$} \\
\hline & Dry unit weight $\gamma_{d}\left(\mathrm{kN} / \mathrm{m}^{3}\right)$ & Moisture content $\omega(\%)$ & & 1 & 3 & 5 & 6 & 7 & 8 & 10 \\
\hline 1 & 16 & 10 & 60 & 1 & 1 & 1 & - & 1 & 0.94 & 0.90 \\
\hline 2 & 16 & 16 & 60 & 1 & 1 & 1 & - & - & 0.93 & 0.91 \\
\hline 3 & 16 & 20 & 60 & 1 & 1 & 1 & 1 & 0.97 & 0.95 & - \\
\hline 4 & 17 & 16 & 60 & 1 & 1 & 1 & - & 1 & - & 0.92 \\
\hline 5 & 17 & 16 & $30 / 60 / 102 / 140$ & - & 1 & - & - & - & - & - \\
\hline
\end{tabular}
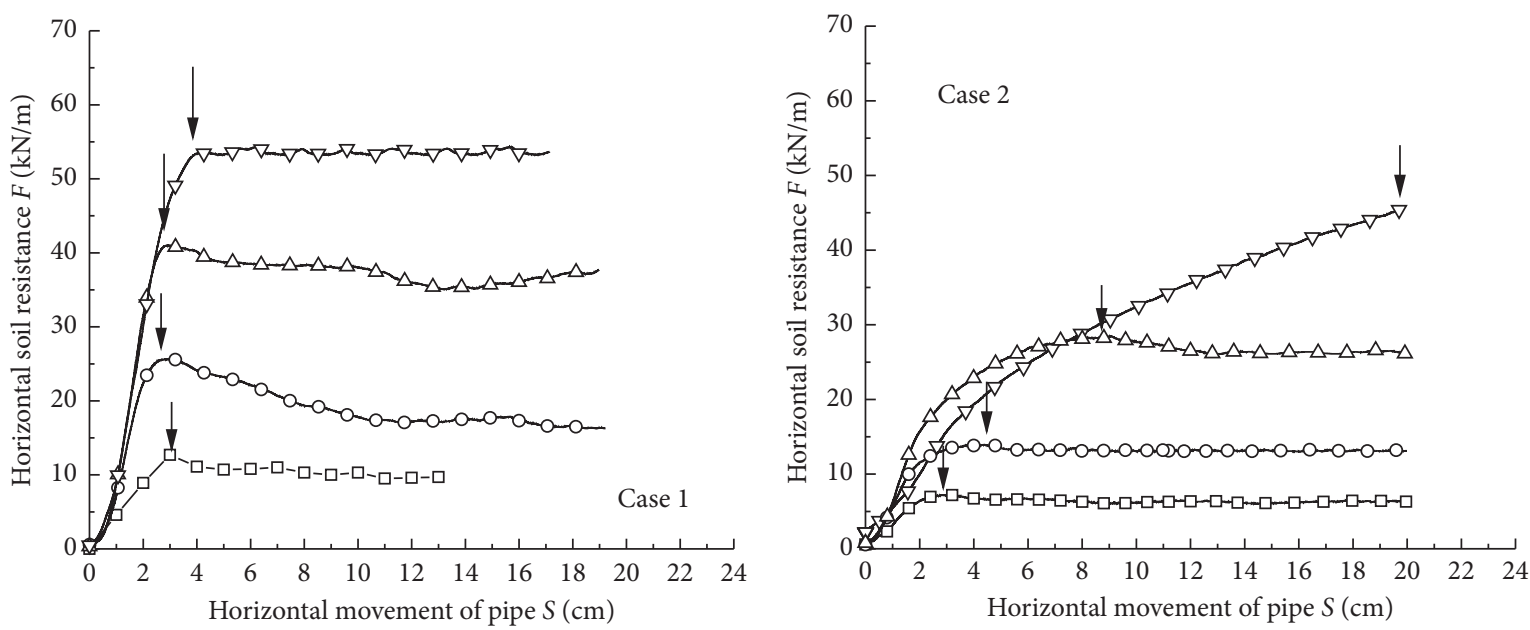

$$
\begin{aligned}
& \multimap-H / D=1 \\
& \multimap-H / D=3
\end{aligned}
$$

(a)

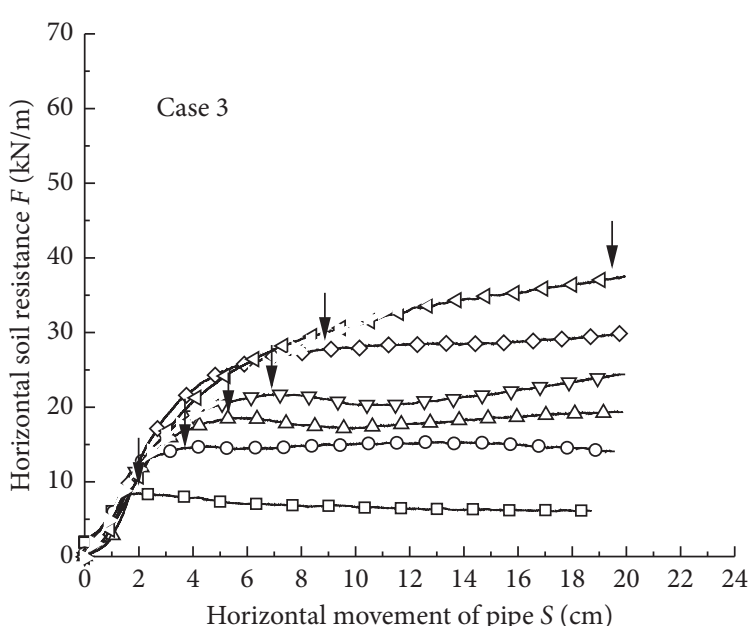

$$
\begin{array}{lll}
\neg-H / D=1 & & -H / D=5 \\
\multimap-H / D=3 & & \checkmark H / D=6 \\
\triangle-H / D=4 & & \checkmark H / D=7
\end{array}
$$

(c)

$$
\begin{array}{llrl}
\rightarrow-H / D=1 & \rightarrow-H / D=5 \\
\neg-H / D=3 & \rightarrow-H / D=8
\end{array}
$$

(b)



$$
\begin{array}{llrl}
\rightarrow-H / D=1 & & -H / D=5 \\
\multimap-H / D=3 & & \rightarrow-H / D=7
\end{array}
$$

(d)

Figure 9: Relationship between lateral soil resistance and deformation. (a) Case 1, (b) Case 2, (c) Case 3, and (d) Case 4. 
diameter ratios is the same. The soil resistance increases linearly with the movement of the pipe and decreases gradually or remains stable after reaching the peak value. The horizontal movement of the pipe corresponding to the peak value of soil resistance is almost the same. However, the resistance-displacement curves in other three cases are different, which show that the soil resistance increases rapidly and nonlinearly in the initial stage, then increases slowly, and the value of soil resistance decreases slightly or remains stable after reaching the peak value. When the depth-diameter ratio is less than 7.0, the peak resistance point in the curve can be marked clearly, but while the depth-diameter ratio exceeds 7.0, the soil resistance still does not reach the peak value even the movement of pipe reaches $20 \mathrm{~cm}$.

These above phenomena may be due to the change of the consistency and ductility of silty clay caused by the moisture content in soil. When the moisture content is $10 \%$, the silty clay is in a stiff state, the faction of binding water among the soil particles is obvious, and the compressibility of soil is weak. When the soil in front and above the pipe reaches the failure state, the bearing capacity of soil reaches the peak value, and the failure of soil represents as brittle failure mode. With the increase of moisture content, the bound water film among soil particles thickens gradually, the cohesion among soil particles weakens, the soil is in a hardplastic or plastic state, and the compressibility enhances. The failure of the soil in front and above the pipe characterizes as local shear failure. Therefore, there is no obvious peak value of soil resistance-displacement curve.

Figure 10 shows the soil resistance-displacement curve of case 5 when $H / D=3$, which indicates that the soil resistance increases with the increase of pipe diameter, and the increase factor is proportional to the pipe diameter. However, the displacement corresponding to the maximum soil resistance is almost the same except for the test at $D=30 \mathrm{~mm}$. We think that the reason for this phenomenon is as follows: when $H / D$ is constant, the pressure of overlying soil on the pipe increases with the increase of pipe diameter, which leads to the increase of soil resistance in the test. However, the interaction area between the pipe and soil also increases with the increase of pipe diameter, and the failure mode of soil around the pipe changes from shear failure of soil cut by the pipe to compression failure of soil squeezed by the pipe. The displacement of the pipe under compression is larger than that under shear, but the displacement is controlled by the mechanical properties of soil around the pipe.

4.2. Failure Mode of Soil Mass. The test results show that the failure modes of the soil around the pipe vary with the increase of the buried depth of pipe. (1) When the depth-diameter ratio of the pipe is small, the horizontal movement of the pipe can cause soil deformation in a certain range above the pipe to reach the surface of soil. That is, pipe movement leads to vertical and oblique cracks in the soil around the pipe, the cracks continue to expand and eventually reach the surface of soil mass, and a wedge-shaped failure body forms. At this moment, the bearing capacity of soil mass reaches its peak. We call this failure mode

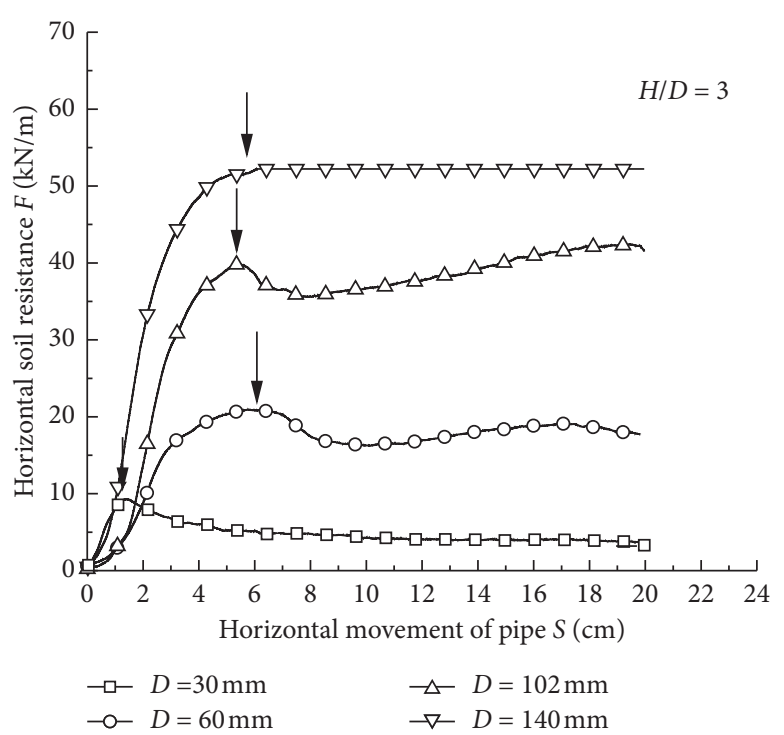

FIgURE 10: Resistance displacement curves of soil with different diameters.

"shallow-buried failure." The peak resistance emerges clearly on the soil resistance-displacement curves, and the pipe displacement corresponding to the peak resistance is small. The reason for this phenomenon is that the buried depth of the pipe is shallow, the Earth pressure acting on pipe wall is very low, and the overlying soil cannot restrict the expansion of cracks in the soil around the pipe. Figure 11(a) shows the photograph and the numerical simulation result of soil failure behind the pipe when $D=60 \mathrm{~mm}$ and $H / D=1$, which is a typical "shallow-buried failure" mode. (2) With the increase of the depth-diameter ratio of the pipe, the crack propagation in the soil around the pipe is limited, and no obvious soil deformation appears on the surface of soil mass. Finally, the soil mass is cut directly by the pipe, which can be called "deep-buried failure." There is no peak resistance point of soil observed on the soil resistance-displacement curves, or the pipe movement is large when the peak soil resistance occurs. The reason is that, with the increase of the depth-diameter ratio of the pipe, the overburden Earth pressure on the pipe increases, and the Earth pressure on the pipe prevents the propagation of cracks, which is manifested as the pipe extrudes the soil in front of it. Figure 11(b) provides the photograph and the numerical result of soil deformation and failure behind the pipe at $D=60 \mathrm{~mm}$ and $H / D=7$, which is characterized by "deep-buried failure" mode.

4.3. Distribution of Earth Pressure on the Pipe. The failure modes of soil mass can be proved with the distribution of Earth pressure on the pipe. Figure 12 presents the distributions of Earth pressure on upstream surface of the pipe of different cases. Due to the close contact between the thin film pressure sensor and the pipe wall during tests, the Earth pressure in the direction of pipe movement is the largest. Figure 12 demonstrates that the Earth pressure acting on the pipe increases with the increase of $H / D$, but the distributions of Earth pressure on the pipe wall under different cases are not consistent. 

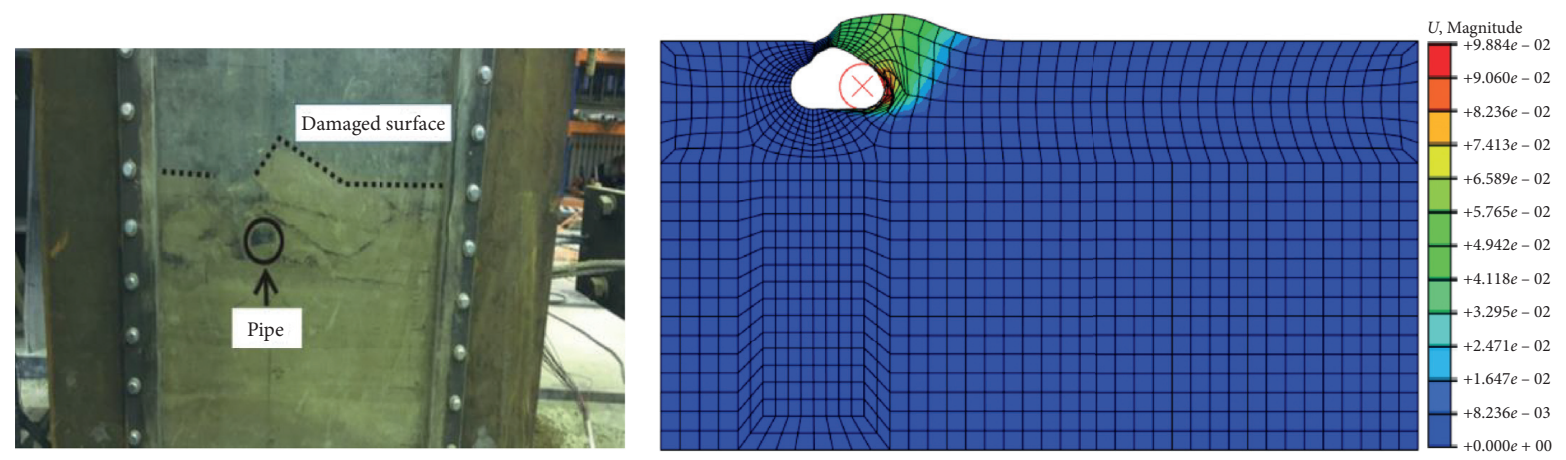

(a)
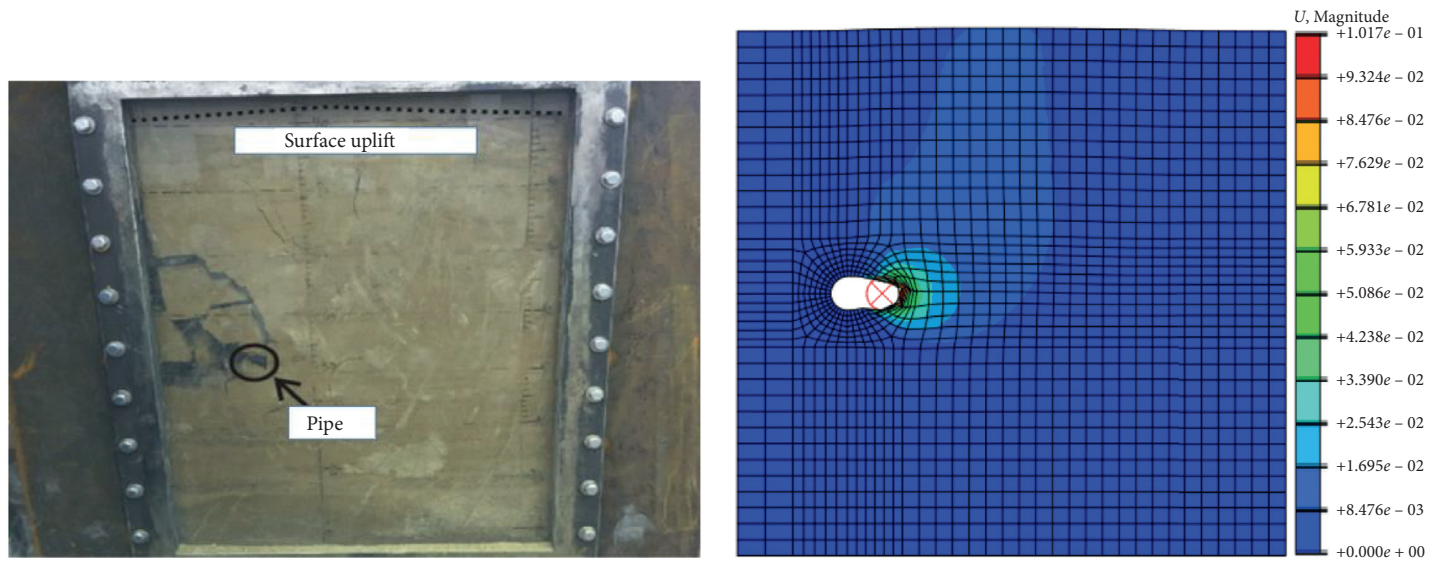

(b)

FIgURE 11: Soil failure modes, in which the left picture is experimental photo and the right picture is the numerical result. (a) $D=60 \mathrm{~mm}$, $H / D=1$; (b) $D=60 \mathrm{~mm}, H / D=7$.

Figure 12(a) shows the distribution of Earth pressure of case 1 , in which the dry unit weight of soil is $16 \mathrm{kN} / \mathrm{m}^{3}$ and moisture content is $10 \%$. As shown in Figure 12(a), the maximum Earth pressure appears at $90^{\circ}$ of the upstream surface of pipe as $H / D$ ranges from 1 to 7 , but when $H / D$ equals 8 and 10, the maximum Earth pressure appears at $120^{\circ}$ and $60^{\circ}$ of the upstream surface of the pipe, which means that the pipe tends to move towards $120^{\circ}$ or $60^{\circ}$ of the upstream surface of the pipe. The reason may be that the soil is stiff and brittle, and the soil homogeneity in the two $H / D$ conditions is not very good due to some reasons in the preparation of tests. The soil damage occurs first in the direction of $120^{\circ}$ or $60^{\circ}$ of the upstream surface of the pipe, respectively, resulting in the maximum Earth pressure appearing at $120^{\circ}$ or $60^{\circ}$ of the upstream surface of the pipe.

Figure 12(b) shows the distribution of Earth pressure of case 2 , in which the dry unit weight of soil is $16 \mathrm{kN} / \mathrm{m}^{3}$ and moisture content is $16 \%$. From Figure 12(b), the maximum Earth pressure appears at $60^{\circ}$ of the upstream surface of the pipe when $H / D$ equals 1 , which indicates that the overburden Earth pressure above the pipe is not enough to limit the movement of the pipe. With the destruction of the soil above the pipe, the pipe moves slant up. In other buried depths, the maximum Earth pressure appears at $90^{\circ}$ of the upstream surface of the pipe, but the pressure on the upper part of the pipe increases rapidly. It shows that the upward and forward movement of the pipe still leads to greater pressure, although the overburden Earth pressure above the pipe restricts the propagation of cracks in the soil around the pipe.

Figure 12(c) shows the distribution of Earth pressure of case 3 , in which the dry unit weight of soil is $16 \mathrm{kN} / \mathrm{m}^{3}$ and moisture content is $20 \%$. Figure 12 (c) indicates that the movement direction of the pipe is well controlled, the maximum Earth pressure appears at $90^{\circ}$ of the upstream surface of the pipe, and the Earth pressure distribution is basically symmetrical. With the increase of $H / D$, the value of Earth pressure increases, but when $H / D$ exceeds 7.0 , the growth rate of Earth pressure in the moving direction slows down.

Figure 12(d) shows the distribution of Earth pressure of case 4 , in which the dry unit weight of soil is $17 \mathrm{kN} / \mathrm{m}^{3}$ and moisture content is $16 \%$. Figure $12(\mathrm{~d})$ demonstrates that the Earth pressure at $90^{\circ}$ of the upstream surface of the pipe is the largest, and the Earth pressure at the upper part of the pipe is higher than that at the lower part. With the increase of $H / D$, the rule of Earth pressure in $90^{\circ}$ of the upstream surface of the pipe varying with $H / D$ is shown as follows: when $H / D$ is less than 7.0, the Earth pressure increases rapidly; when $H / D$ is greater than 7.0, the increase becomes smaller; when $H / D$ is greater than 15.0, the increase increases again.

According to the distribution of Earth pressure acting on the pipe, because the upper surface of site is free, the pipe moves upward and forward, and the Earth pressure 


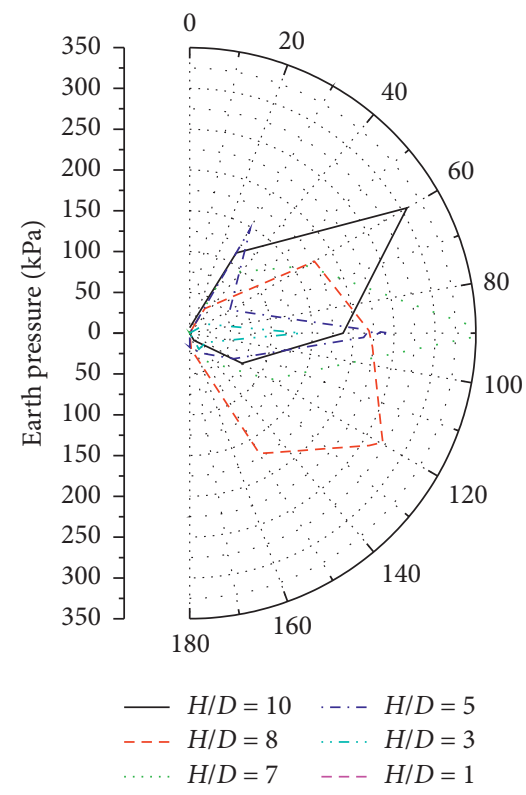

(a)

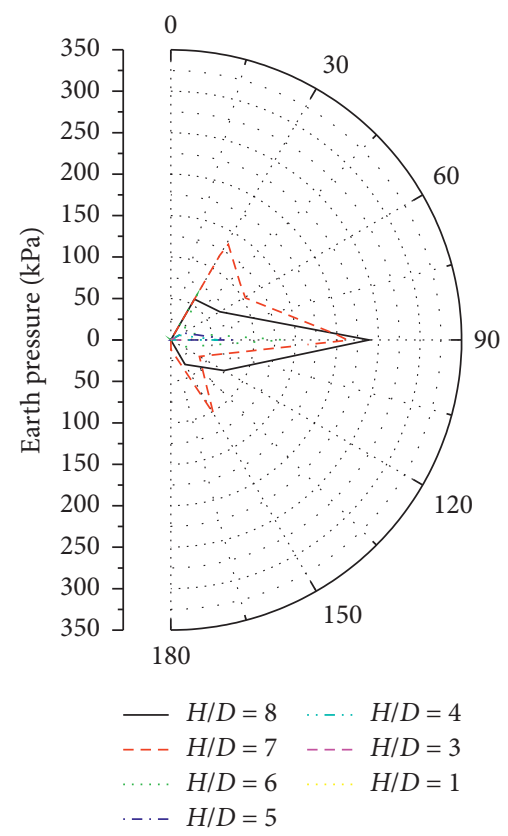

(c)

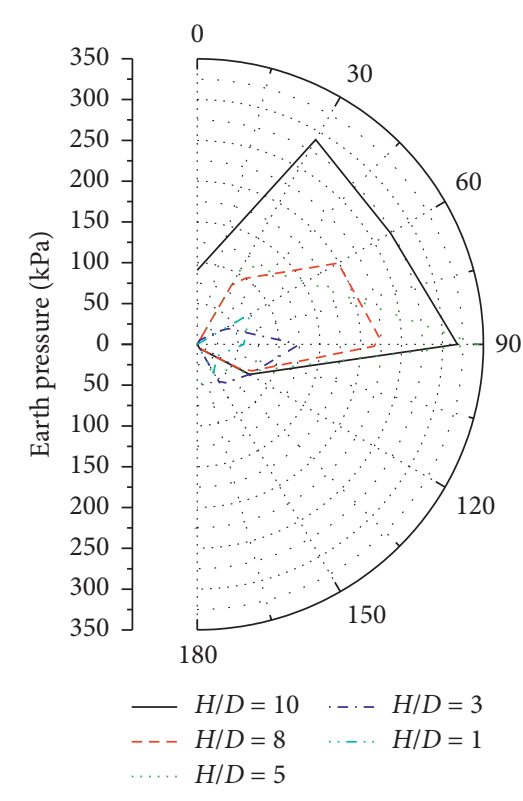

(b)

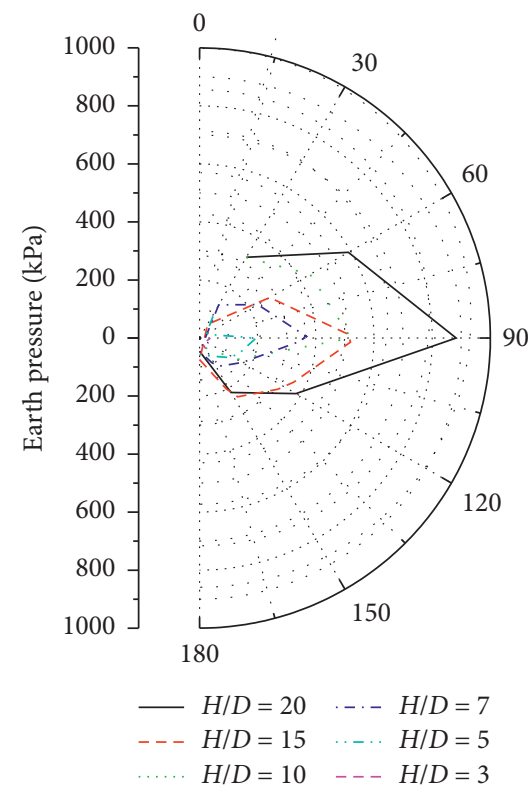

(d)

Figure 12: Distribution of Earth pressure on upstream surface of the pipe. (a) Case 1, (b) Case 2, (c) Case 3, and (d) Case 4.

distribution around the pipe shows that the Earth pressure at the upper part of pipe is greater than that at the lower part. With the increase of buried depth of the pipe, the constraint of soil on the pipe increases, and the failure mode of soil mass changes from "shallow-buried failure" to "deep-buried failure." As shown in Figure 12, with the increase of dry unit weight, the soil becomes more and more dense, and its ability to resist deformation and failure becomes stronger, so the Earth pressure acting on the pipe is greater. The moisture content has a certain influence on the failure of soil mass, but has little effect on the value of Earth pressure.
4.4. Peak Resistance of Soil Mass $\left(F_{m}\right)$. According to the failure mode of soil around the pipe, when the pipe moves, Peng [29] used the limit equilibrium method of soil to analyse the peak resistance of soil in pipe-soil interaction and suggested using the passive Earth pressure formula to obtain the peak resistance of soil when the pipeline moves horizontally. In order to study the pipe-soft clay interaction in the buckling process of submarine pipelines, based on Peng's works [29], Wang [30] suggested using formula (2) to calculate the horizontal peak resistance of soft clay, considering the cohesion effect of clay: 


$$
F_{m}=B_{2}\left[\frac{1}{2} \gamma\left(H_{1}+D\right)^{2} K_{p}+2 c\left(H_{1}+D\right) \sqrt{K_{p}}\right],
$$

where $F_{m}$ presents the horizontal peak resistance of soil subjected to unit length pipe section, unit: $\mathrm{kN} / \mathrm{m}, B_{2}=2.04$ $\left(H_{1} / \mathrm{D}\right)-0.5$ is a dimensionless correction coefficient, $K_{p}=\tan ^{2}(45+\varphi / 2)$ is the passive Earth pressure coefficient, $c$ is cohesive force of soil, unit: $\mathrm{kPa}, \varphi$ is internal friction angle of soil, unit: degree $\left({ }^{\circ}\right), \gamma$ is the natural unit weight of overlying soil, $\gamma=(1+\omega) \gamma_{d}$, unit: $\mathrm{kN} / \mathrm{m}^{3}, D$ is pipe diameter, unit: $\mathrm{m}$, and $H_{1}$ is thickness of covering soil, unit: $\mathrm{m}$.

Essentially, the methods proposed by Peng [29] and Wang [30] suppose that the soil in front of the pipe is in the passive critical state when the soil destroy due to the interaction between the pipe and soil, and the peak resistance of the soil is calculated by modifying the passive Earth pressure. The passive Earth pressure formula has clear physical meaning, but the Earth pressure distribute forms on pipe and retaining wall are different, so the calculation results of passive Earth pressure need to be revised. Wang's method [30] is proposed for soft clay, and its applicability to silty clay in Beijing region will be validated through test. Because the assumption of buried depth $H$ in our tests is different from Wang's work [30], formula (2) is transformed into formula (3) to calculate the peak resistance of silty clay:

$$
F_{m}=B\left[\frac{1}{2} \gamma\left(H+\frac{D}{2}\right)^{2} K_{p}+2 c\left(H+\frac{D}{2}\right) \sqrt{K_{p}}\right],
$$

where $B$ is a dimensionless correction coefficient and $H$ indicates the distance from the ground surface to the centre of pipe. Other symbols are the same as formula (2).

Next, we will discuss the parameter $B$ in formula (3).

Figure 13 shows the relationship between the dimensionless correction coefficient $B$ and the depth-diameter ratio $H / D$ of the pipe, in which $B$ is the ratio of the peak resistance of soil obtained from tests to the calculated passive Earth pressure. It can be seen from Figure 13 that the value of $B$ can be fitted by a formula similar to that in formula (2), as shown in formula (4), but the fitting parameters $a$ and $b$ are affected by the consistency state and the dry unit weight of soil around the pipe. The parameter $a$ increases with the increase of dry unit weight of soil, but decreases first and then increases with the increase of water content when the dry unit weight of soil is constant. That is, when the moisture content is less than the plastic limited moisture content, the parameter $a$ decreases with the increase of the moisture content; otherwise, the parameter $a$ increases with the increase of the moisture content. The parameter $b$ decreases approximately linearly with the increase of moisture content, the dry unit weight of soil has little effect on it. The values of $a$ and $b$ can be determined from formulae (5) and (6):

$$
\begin{aligned}
& B=a\left(\frac{H}{D}\right)^{b}, \\
& a=\left(a_{1}+b_{1} \omega+c_{1} \omega^{2}\right)\left(\frac{\gamma}{(1+\omega) \gamma_{w}}\right)^{d_{1}}, \\
& b=a_{2}+b_{2} \omega,
\end{aligned}
$$



FIgURE 13: Relations between $B$ and $H / D$.

where $\gamma$ is the natural unit weight of overlying soil, unit: $\mathrm{kN} /$ $\mathrm{m}^{3}, \gamma_{\omega}$ is the unit weight of water, unit: $\mathrm{kN} / \mathrm{m}^{3}, \omega$ is the moisture content, and $a_{1}, b_{1}, c_{1}, d_{1}, a_{2}$, and $b_{2}$ are fitting parameters.

Based on the experimental results of $60 \mathrm{~mm}$ diameter pipe, the parameters in formulae (5) and (6) are obtained, that is, $a_{1}=0.00917, b_{1}=-0.126, c_{1}=0.478, d_{1}=11.433$; $a_{2}=0.187$, and $b_{2}=-1.20$. Figure 14 (a) shows the comparison between the parameter $a$ calculated from the formula (5) and that obtained from the experiments, which indicates that the coincidence is very good. Figure 14(b) presents the result of the comparison between the parameter $b$ calculated from formula (6) and that obtained from experiments, which demonstrates that the fitting effect is also very good.

After the above six parameters related to the moisture content and the dry unit weight of soil are determined, the peak soil resistance on the buried pipe can be calculated with formulae (3)-(6).

Now, using the experimental results of case 5 to verify the applicability and investigate the accuracy of the proposed method, Figure 15 shows the comparison of the experimental data with the calculated results from formula (3) in this paper, Peng's method [29], Wang's method [30], and ALA method [25]. As can be seen from Figure 15, the results obtained from formula (3) and the corresponding parameters in this paper are in the best agreement with the experimental results. The results of the ALA method [25] are slightly higher than the experimental results. The results obtained from Peng's method [29] are much smaller than experimental results because the influence of cohesion between clay particles is not considered. The results obtained from Wang's method [30] are much higher than experimental results. The reason is that Wang's method [30] is for saturated soft clay in Bohai region. Although the form of correction coefficient $B_{2}$ is similar to that in this paper, Wang's method [30] does not consider the influence of moisture content and dry unit weight of soil on the $B_{2}$ value. Moreover, the grain composition and structure of saturated soft clay in Bohai region are different from that of silty clay in 




(a)

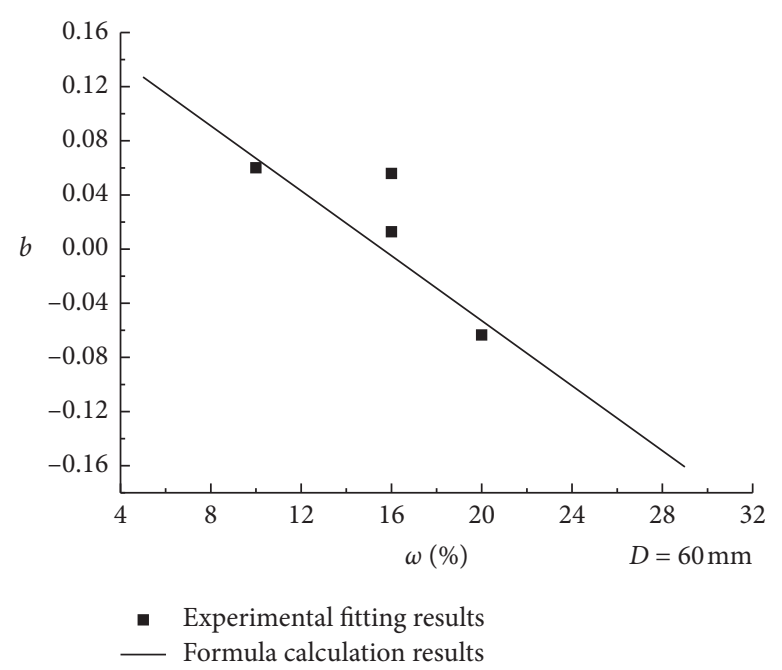

(b)

Figure 14: Comparison between the result via formula and test result. (a) Variation of parameter $a$ with $\omega$ and $\gamma$. (b) Relationship between parameter $b$ and $\omega$.

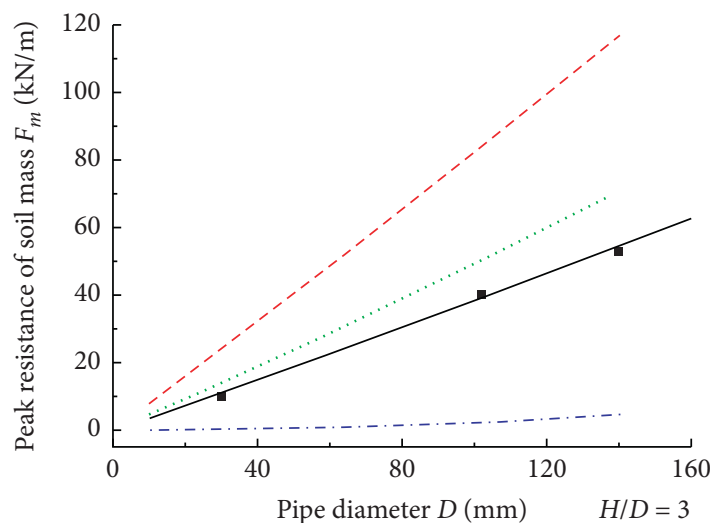

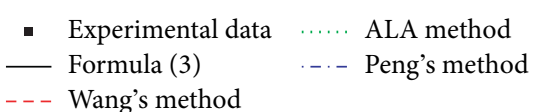

FIGURE 15: Comparison of model test results and formula results, in which $H / D=3$.

Beijing region. Therefore, Wang's method [30] cannot be employed directly to the silty clay in Beijing region.

In order to further verify the applicability of formula (3), the pipe-soil interaction is numerically calculated under different $H / D=1,3,5,7$, in which the site consists of soil IV, as shown in Table 1, and the pipe diameter is $90 \mathrm{~mm}$. The numerical method used has been described previously. Figure 16(a) shows the soil resistance displacement curve calculated by the numerical method. Figure 16(b) presents the peak resistance is obtained by formula (3), ALA method [25], and numerical calculation, which indicates that the results obtained by formula (3) is in good agreement with the numerical results; the ALA method [25] overestimates the horizontal binding force on the pipe when the depth-diameter ratio is less than 3 and underestimates the horizontal binding force on the pipe, while the depth-diameter ratio is greater than 3 .
From the above analysis, formula (3) proposed in this paper is based on the pipe-soil interaction test of silty clay in Beijing region, takes into account the variation of correction coefficient $B$ with soil moisture content and dry unit weight, and is suitable for calculating the horizontal peak resistance of silty clay in Beijing region. However, it is noted that experimentally determined parameters required for the model are necessary when applying this method to other cohesive soil areas.

4.5. Displacement Corresponding to Peak Resistance $\left(S_{m}\right)$. Figure 17(a) describes the relationship between $S_{m}$ and $H / D$. The abscissa represents the depth-diameter ratio $H / D$, and the ordinate represents the displacement $S_{m}$ corresponding to the peak resistance. We find that the displacement $S_{m}$ increases with the increase of the depth-diameter ratio of the pipe except for case 1 . As mentioned above, the reason for this phenomenon is that the soil is in a stiff state in case 1, the compressibility of the soil is poor, and the resistance provided by the soil rapidly reaches the peak value during pipe movement. In the other three cases, with the increase of moisture content of the soil, the test soil is in the hard plastic/plastic state and it has a strong compressibility; thus, the displacement $S_{m}$ increases with the increase of the depth-diameter ratio. Meanwhile, as shown in Figure 10, the diameter of the pipe has little effect on the displacement corresponding to the peak resistance.

Based on the above discussion, the following suggestions are given. When the moisture content is less than the plastic limited moisture content, i.e., $\omega \leq 15 \%$ in this paper, the displacement corresponding to the peak resistance is proposed to be $30 \mathrm{~mm}$; when the moisture content is greater than the plastic limited moisture content, the displacement corresponding to the peak resistance is determined from formula (7). Figure 17(b) compares the results calculated from formula (7) with the experimental results, which indicates that formula (7) can well represent the change of $S_{m}$ : 


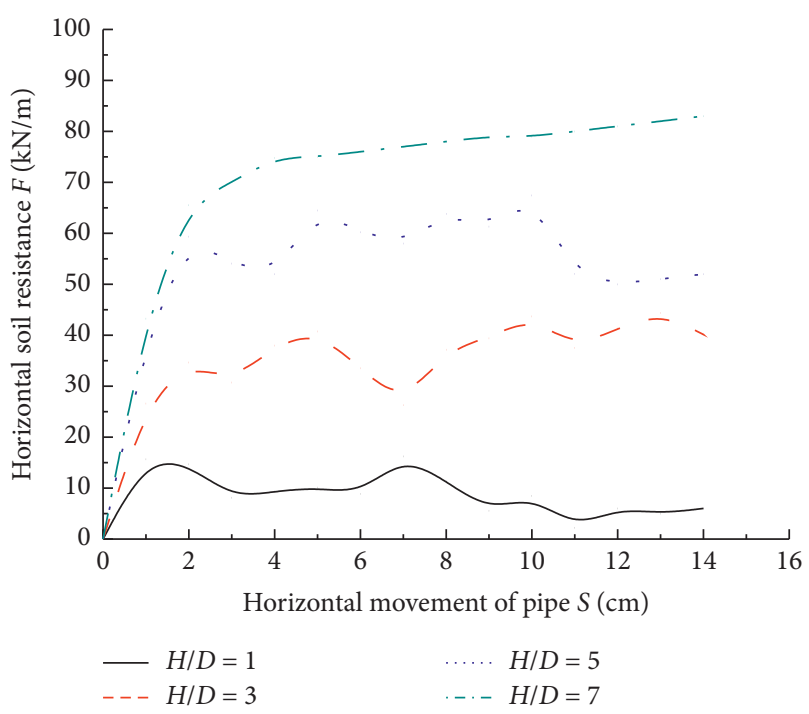

(a)

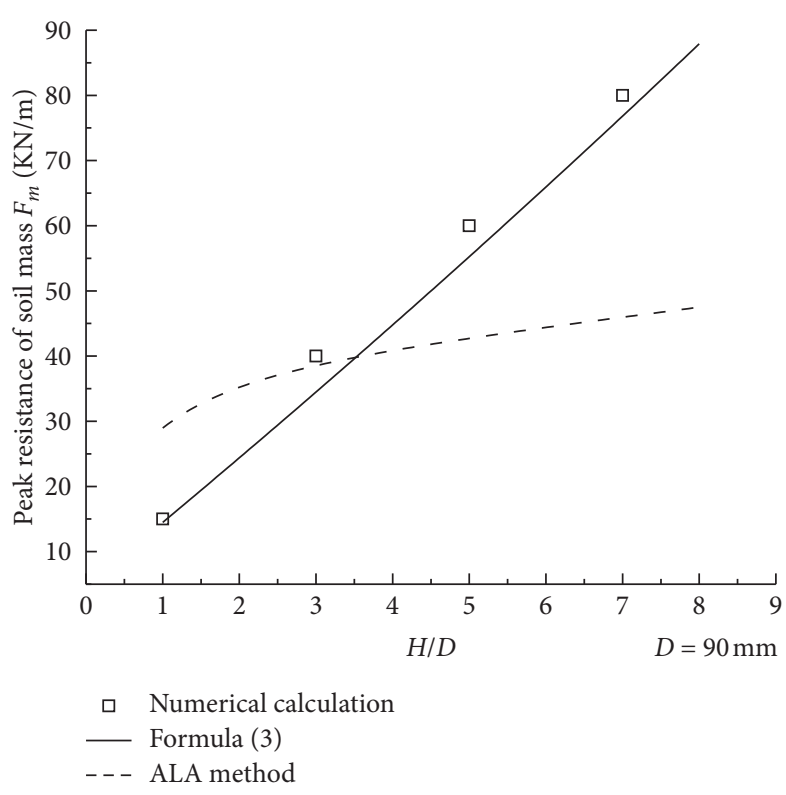

(b)

FIgURE 16: The comparison of formula (3) to the ALA method. (a) Soil resistance displacement curve calculated by the numerical method. (b) The peak resistance obtained by formula (3), ALA method, and numerical calculation.

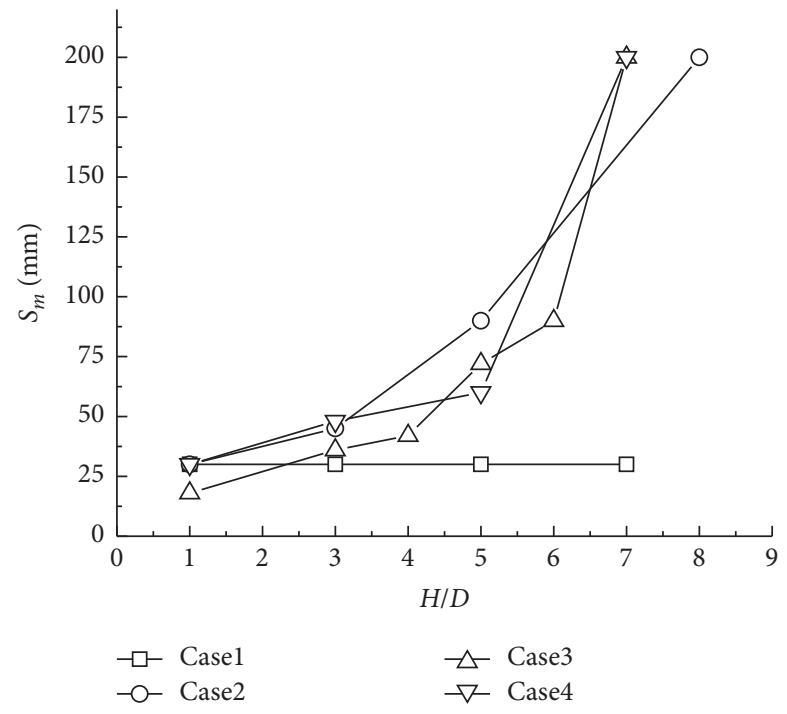

(a)

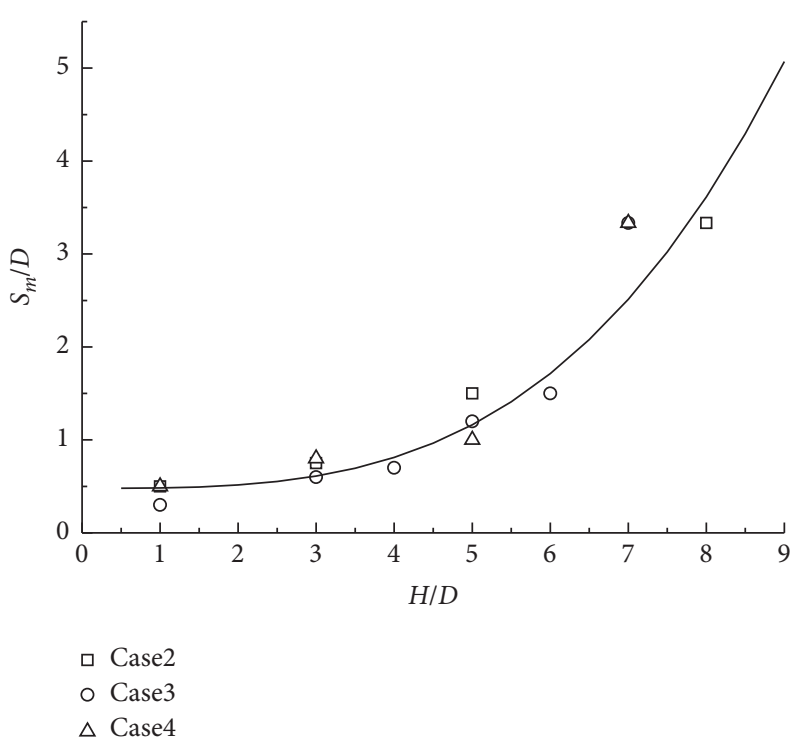

(b)

Figure 17: Plot of $S_{m}$ versus H/D. (a) Experimental data. (b) Comparison between the results calculated from formula (7) and the experimental results.

$$
\frac{S_{m}}{D}=0.0037 \times\left(\frac{H}{D}\right)^{3.242}+0.48
$$

4.6. Soil Spring Coefficient. As mentioned above, it is customary to simplify the resistance-displacement curve of soil before the peak resistance reached to the linear relationship shown in Figure 1. Thus, the whole resistance-displacement curve can obtained after determining the peak resistance of soil and the corresponding displacement. This treatment method cannot describe the nonlinear characteristics of the prefailure deformation of the soil around the pipe. Figures 9 and 10 show that the resistance-displacement curve (F-S curve) of the soil around the pipe can be fitted with the hyperbola shown in formula (8). Therefore, following the deduction idea of Duncan and Chang model of soil [31], a nonlinear expression of the soil spring coefficients of the 




(a)

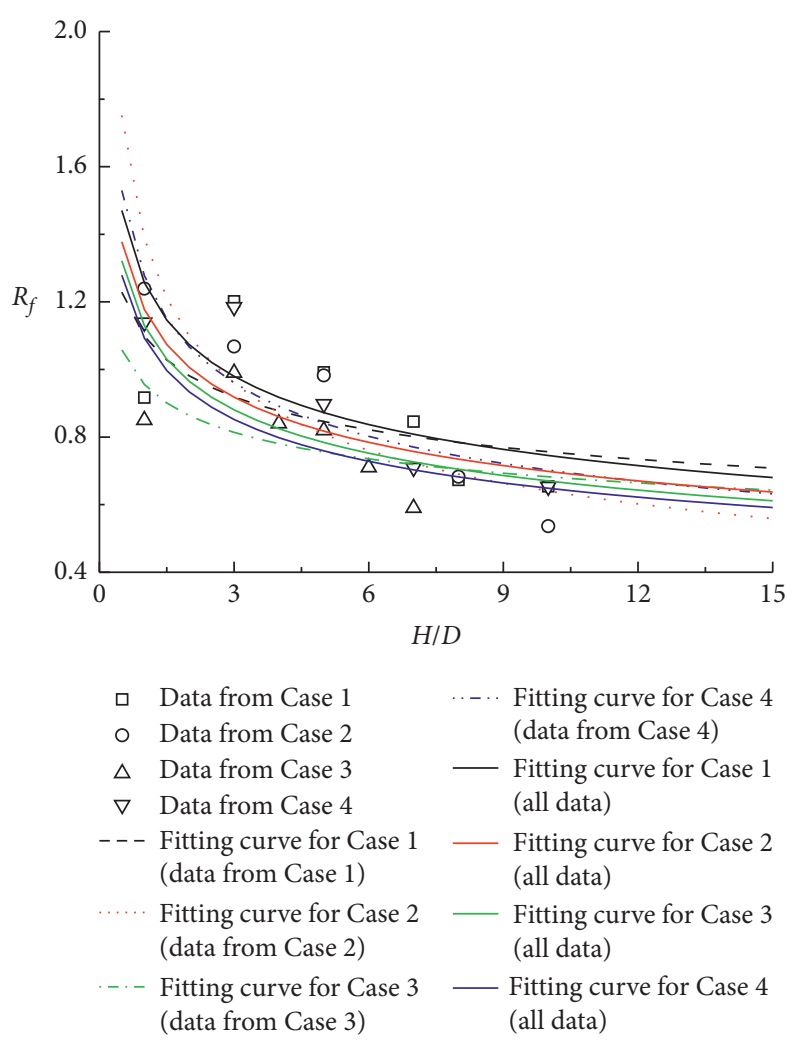

(b)

Figure 18: Fitting curve of $K_{i}$ and $R_{f}$. (a) $K_{i}$ versus $H / D$. (b) $R_{f}$ versus $H / D$.

pipe-soil interaction is constructed, as shown in formula (9) or (10):

$$
F=\frac{S}{a+b S}
$$

in which $a=1 /(F / S)_{\mathrm{i}}=1 / K_{i}$ is the reciprocal of initial stiffness coefficient of soil spring and $b=1 / F_{\text {ult }}, F_{\text {ult }}$ is the soil resistance corresponding to asymptotic line:

$$
\begin{aligned}
& K_{t}=K_{i}\left[1-R_{f} \frac{F}{F_{m}}\right]^{2}, \\
& K_{t}=\frac{1}{K_{i}\left(\left(1 / K_{i}\right)+\left(R_{f} S / F_{m}\right)\right)^{2}},
\end{aligned}
$$

in which $K_{t}$ is tangent stiffness coefficient of soil spring, $K_{i}$ indicates the initial stiffness coefficient of soil spring, $R_{f}$ denotes the damage ratio, and $R_{f}=F_{m} / F_{\text {ult }}$.

Figure 18 shows the change of the initial stiffness coefficient of soil spring $K_{i}$ and of the damage ratio $R_{f}$ following the depth-diameter ratio $H / D$. As shown in Figure 18(a), the initial stiffness coefficient of soil spring $K_{i}$ decreases with the increase of $H / D$, but the relationship curves are different under different site conditions, which means that the initial stiffness coefficient of soil spring $K_{i}$ is affected by the pressure of overlying soil and the depth-diameter ratio $H / D$. Therefore, formula (11) is suggested to describe the relationship among them:

$$
K_{i}=k_{K}\left(\frac{H}{D}\right) p_{a}\left(\frac{\gamma H}{p_{a}}\right)^{n_{K}}
$$

in which $p_{a}$ means atmospheric pressure value, and $p_{a}=101.4 \mathrm{kPa}, \gamma$ is the natural unit weight of overlying soil, and $k_{K}$ and $n_{K}$ are test parameters, which may be determined readily from the results of a series of tests by plotting the values of $K_{i} /\left(p_{a} H / D\right)$ against $\gamma H / p_{a}$ on log-log scales and fitting a straight line to the data, as shown in Figure 19(a).

Similarly, the relationship among the damage ratio $R_{f}$, the overburden pressure $\gamma H$, and the depth-diameter ratio $H / D$ are obtained:

$$
R_{f}=k_{R}\left(\frac{H}{D}\right)\left(\frac{\gamma H}{p_{a}}\right)^{n_{R}},
$$

in which $k_{R}$ and $n_{R}$ are test parameters, which may be determined readily from the results of a series of tests, as shown in Figure 19(b).

The fitting curves of $K_{i}$ and $R_{f}$ are shown in Figure 18, and the above parameters obtained from the experiments are listed in Table 4 . As can be seen from Table 4, the parameter $n_{K}$ and $n_{R}$ are less than zero, and the parameters $k_{K}$ and $n_{K}$ decrease with the increase of moisture content, and increases with the increase of dry unit weight. However, there is no obvious change rule in $k_{R}$ and $n_{R}$. The bottom row of Table 4 gives the fitting parameters based on all data, which take into account the effects of soil dry unit weight, moisture content 




(a)


(b)

FIGURE 19: Fitting process curve. (a) $K_{i} /\left(p_{a} H / D\right)$ versus $\gamma H / p_{a}$. (b) $R_{f} /(H / D)$ versus $\gamma H / p_{a}$.

TABle 4: Parameters for describing nonlinear spring of soil.

\begin{tabular}{lcccccrrr}
\hline \multirow{2}{*}{ Case } & Dry unit weight $\left(\mathrm{kN} / \mathrm{m}^{3}\right)$ & Moisture content $(\%)$ & $k_{K}$ & $n_{K}$ & $k_{R}$ & \multicolumn{2}{c}{$\begin{array}{c}\text { Adj. R-Square } \\
n_{R}\end{array}$} \\
\hline 1 & 16 & 10 & 0.0700 & -1.3799 & 0.00546 & -1.1620 & 0.9637 & 0.9561 \\
2 & 16 & 16 & 0.0094 & -1.9226 & 0.00335 & -1.3358 & 0.9426 & 0.9795 \\
3 & 16 & 20 & 0.0013 & -2.5312 & 0.00564 & -1.1463 & 0.9559 & 0.9613 \\
4 & 17 & 16 & 0.0503 & -1.3856 & 0.00469 & -1.2599 & 0.9830 & 0.9810 \\
& & & 0.0148 & -1.7598 & 0.00465 & -1.2267 & 0.8952 & 0.9672 \\
\hline
\end{tabular}

of soil, and depth-diameter ratio $H / D$. The value of Adj. R-Square indicates that the fitting from formulae (11) and (12) have high accuracy.

The tangent stiffness coefficient of soil spring in the process of pipe-soil interaction can be determined from formula (9) or (10) after the peak resistance of soil is obtained from formulae (3)-(6), based on formulae (11) and (12), and Table 4.

\section{Conclusions}

The process of soil resistance in horizontal movement of pipe is studied based on physical model tests of soil-pipe interaction in silty clay field in Beijing region, in which some influence factors are considered, such as pipe diameters, soil consistency state, dry unit weight, and depth-diameter ratio. The paper focuses on the failure modes of soil, the peak resistance of soil, the corresponding displacement to peak resistance, and the nonlinear property of silty clay spring.

When the moisture content of soil is lower than the plastic limited moisture content, the horizontal resistancedisplacement curve of soil before the peak resistance reached is approximately linear, and the displacement corresponding to the peak resistance is very small, about $30 \mathrm{~mm}$, and is not affected by the change of depth-diameter ratio. When the moisture content of soil is higher than the plastic limited moisture content, the soil resistance increases quickly at first, then gradually becomes gentle; the displacement corresponding to the peak resistance increases gradually with the increasing of the depth-diameter ratio.

The failure modes of soil under deep buried condition and shallow buried condition of the pipe are different. The ALA method can be used to estimate the peak soil resistance of silty clay sites in Beijing region when the depth-diameter ratio is less than or equal to 3 , but the results are slightly overestimated, and Wang's method cannot be applied directly to the silty clay in Beijing region. A method for determining the peak resistance of silty clay in Beijing region is proposed.

The nonlinear properties of silty clay spring can be described from formulae (9) or (10).

The displacement expression given by formula (7) is obtained from the condition of $60 \mathrm{~mm}$ pipe diameter, which needs to be verified for other pipe diameter conditions. 


\section{Data Availability}

All data, models, and code generated or used during the study are included within the article.

\section{Conflicts of Interest}

The authors declare that there are no conflicts of interest regarding the publication of this paper.

\section{Acknowledgments}

The authors acknowledge the Scientific Research Fund of Institute of Engineering Mechanics, China Earthquake Administration (Grant no. 2018D09) and National Natural Science Foundation of China (Grant no. 51808018), for the financial assistance that made this investigation possible.

\section{References}

[1] B. Dadfar, M. Hesham El Naggar, and M. Nastev, "Ovalization of steel energy pipelines buried in saturated sands during ground deformations," Computers and Geotechnics, vol. 69, pp. 105-113, 2015.

[2] T. Sheldon, H. Sezen, and I. Moore, "Beam-on-Springs modeling of jointed pipe culverts," Journal of Performance of Constructed Facilities, vol. 30, no. 2, Article ID 04015002, 2016.

[3] V. E. Melissianos, G. P. Korakitis, C. J. Gantes, and G. D. Bouckovalas, "Numerical evaluation of the effectiveness of flexible joints in buried pipelines subjected to strike-slip fault rupture," Soil Dynamics and Earthquake Engineering, vol. 90, pp. 395-410, 2016.

[4] V. E. Melissianos, D. Vamvatsikos, and C. J. Gantes, "Performance-based assessment of protection measures for buried pipes at strike-slip fault crossings," Soil Dynamics and Earthquake Engineering, vol. 101, pp. 1-11, 2017.

[5] S. Hamzeh and J. Vahid, "Intensity measures for the assessment of the seismic response of buried steel pipelines," Bulletin of Earthquake Engineering, vol. 14, pp. 1265-1284, 2016.

[6] X. Liu, H. Zhang, K. Wu, M. Xia, Y. Chen, and M. Li, "Buckling failure mode analysis of buried X80 steel gas pipeline under reverse fault displacement," Engineering Failure Analysis, vol. 77, pp. 50-64, 2017.

[7] B. Dezhkam and A. Z. Nouri, "Dynamic response of nanoparticle-water pipes buried in the soil subjected to far-fault earthquake using numerical method," Soil Dynamics and Earthquake Engineering, vol. 113, pp. 174-179, 2018.

[8] X. Liu, H. Zhang, B. Wang et al., "Local buckling behavior and plastic deformation capacity of high-strength pipe at strikeslip fault crossing," Metals, vol. 8, no. 22, 2018.

[9] Z. Zhong, S. Wang, M. Zhao, X. Du, and L. Li, "Performance of ductile iron push-on joints rehabilitated with CIPP liner under repetitive and seismic loadings," Soil Dynamics and Earthquake Engineering, vol. 115, pp. 776-786, 2018.

[10] Y. S. Hsu, "Finite element approach of the buried pipeline on tensionless foundation under random ground excitation," Mathematics and Computers in Simulation, vol. 169, pp. 149-165, 2020.

[11] J. M. E. Audibert and K. J. Nyman, "Soil restraint against horizontal motion of pipes," Journal of the Geotechnical Engineering Division, vol. 103, no. 12, pp. 1119-1142, 1977.
[12] C. H. Trautmann, T. D. O’Rourfce, and F. H. Kulhawy, "Uplift force-displacement response of buried pipe," Journal of Geotechnical Engineering, vol. 111, no. 9, pp. 1061-1076, 1985.

[13] S. Yimsiri, K. Soga, K. Yoshizaki, G. R. Dasari, and T. D. O'Rourke, "Lateral and upward soil-pipeline interactions in sand for deep embedment conditions," Journal of Geotechnical and Geoenvironmental Engineering, vol. 130, no. 8, pp. 830-842, 2004.

[14] P. J. Guo and D. F. E. Stolle, "Lateral pipe-soil interaction in sand with reference to scale effect," Journal of Geotechnical and Geoenvironmental Engineering, vol. 131, no. 3, pp. 338349, 2005.

[15] K. Badv and KE. Daryani, "An investigation into the upward and lateral soil-pipeline interaction in sand using finite difference method," Iranian Journal of Science and Technology, Tansaction B: Engineering, vol. 34, no. B4, pp. 433-445, 2010.

[16] R. Liu, SW. Yan, HB. Wang et al., "Model tests on soil restraint to pipelines buried in sand," Chinese Journal of Geotechnical Engineering, vol. 33, no. 4, pp. 559-565, 2011, in Chinese.

[17] J. K. Jung, T. D. O’Rourke, and N. A. Olson, "Lateral soil-pipe interaction in dry and partially saturated sand," Journal of Geotechnical and Geoenvironmental Engineering, vol. 139, no. 12, pp. 2028-2036, 2013.

[18] LY. Li and JL. Li, "Ultimate soil bearing capacity of lateral pipeline-sand interaction," Journal of Beijing University of Technology, vol. 42, no. 6, pp. 933-938, 2016, in Chinese.

[19] D. J. Robert, K. Soga, T. D. O’Rourke et al., "Lateral loaddisplacement behavior of pipelines in unsatuarated sands," Journal of Geotechnical and Geoenvironmental Engineering, vol. 142, no. 11, 2016.

[20] J. Oliveira, M. Almeida, M. Almeida et al., "Physical modeling of lateral clay-pipe interaction," Journal of Geotechnical and Geoenvironmental Engineering, vol. 136, no. 7, pp. 950-956, 2009.

[21] R. Liu, S. Z. Guo, H. B. Wang et al., "Soil resistance acting on buried pipelines in Bohai Bay soft clay," Chinese Journal of Geotechnical Engineering, vol. 35, no. 5, pp. 961-967, 2013, in Chinese.

[22] R. Liu, S. Yan, and X. Wu, "Model test studies on soil restraint to pipeline buriedin Bohai soft clay," Journal of Pipeline Systems Engineering and Practice, vol. 4, no. 1, pp. 49-56, 2013.

[23] R. Liu, P. Basu, and H. Xiong, "Laboratory tests and thermal buckling analysis for pipes buried in Bohai soft clay," Marine Structures, vol. 43, pp. 44-60, 2015.

[24] GB50032-2003, "Code of seismic design of outdoor water supply, sewerage, gas and heating engineering," Ministry of Construction of the People's Republic of China, Beijing, China, 2003.

[25] American Lifelines Alliance, "Guidelines for the design of buried steel pipe," Federal Emergency Management Agency (FEMA), Washington, D.C., USA, 2001, http://www. americanlifelinesalliance.org.

[26] C. G. Zhang and H. J. Zhang, "Experiment study on the relationship between water content and shear strength parameters of silty clay," Journal of North China Institute of Science and Technology, vol. 2, pp. 27-29, 2011, in Chinese.

[27] L. Li, X. Liu, X. Du et al., "Analysis on numerical simulation model for seismic response of a buried pipeline," Earthquake Engineering and Engineering Dynamics, vol. 35, no. 6, pp. 106-113, 2015, in Chinese.

[28] Z. Y. Ou, "Analysis and design theory and practice of deep excavation engineering," Science and technology books Co., Ltd., Taipei, China, 2002, in Chinese. 
[29] L. C. Peng, "Stress analysis methods for underground pipelines," Pipeline Industry, vol. 47, no. 5, pp. 65-74, 1978.

[30] H. B. Wang, "Study on the interaction between soil and submarine pipeline in lateral buckling mode," M. Eng. thesis, Tianjin University, Tianjin, China, 2010.

[31] J. M. Duncan and C. Y. Chang, "Nonlinear analysis of stress and strain in soils," Journal of Soil Mechanics and Foundations Division, ASCE, vol. 96, no. SM5, pp. 1629-1653, 1970. 